\title{
The Dilapidations Protocol: Third edition
}

Received (in revised form): 22nd July, 2008

\begin{abstract}
Jacqui Joyce
is a partner in the Property Dispute Resolution Department at Thomas Eggar LLP and is Chair of the Law Reform Committee of the Property Litigation Association. Recognised as a 'leader in her field' by Chambers UK, she is also an experienced mediator in the area of property cases and general contract/tort claims. She is a member of the 'Sounding Board' advising the Law Commission on changes to the law of forfeiture and the Government panel reviewing the changes to the Landlord and Tenant Act 1954 and alienation, and is a member of the RICS committee considering revisions of the PACT scheme for lease renewals.
\end{abstract}

Correspondence: Jacqui Joyce, Thomas Eggar LLP, 76 Shoe Lane, London EC4A 3JB, UK; Tel: + 44 (0)20 7842 3892 ; Fax: + 44 (0)20 7842 3902; E-mail: jacqui.joyce@thomaseggar.com

\begin{abstract}
In May 2008 the Property Litigation Association issued the third edition of its Dilapidations Protocol. This deals with claims for damages by a landlord at the end of a lease arising out of breaches of covenant by the tenant relating to the physical state of the premises, for example, repair, redecoration, reinstatement. This paper gives a brief guide to the history and workings of the Protocol. Journal of Building Appraisal (2008) 4, 55-58. doi:10.1057/jba.2008.23
\end{abstract}

\section{Keywords:}

dilapidations, damages, repair, reinstatement, endorsement

\section{INTRODUCTION}

In May 2008 the Property Litigation Association issued the third edition of its

Dilapidations Protocol. This paper gives a brief guide to the history and workings of the Protocol. A step by step guide to the Protocol is shown in Figure 1.

The revised protocol takes account of the unease expressed by surveyors about giving an endorsement that the amount claimed was a 'fair assessment of the landlord's loss'. The revised endorsement relates to the works that are required, the cost thereof and supersession issues.

\section{WHY HAVE A PROTOCOL?}

The Protocol (which is formally endorsed by the Royal Institution of Chartered Surveyors ('RICS')) was first launched in Spring 2002 to deal with disputes arising from the physical state of premises at the termination of a tenancy.

Its aim, like all protocols, is to encourage the parties to have proper pre-action contact and for the early exchange of information in the hope that the dispute can be resolved without the need for proceedings.

Before the introduction of the Protocol, it was common for landlords to instigate proceedings for damages at an early stage in the dispute. It was also common for parties to take exaggerated stances. Landlords would often serve over inflated claims with the rationale they would be 'negotiated' down, while tenants would respond in a similar vein by making minimal offers, if any.

It was only when the landlord was faced with producing evidence as to any diminution in the value of its reversion (to deal with the statutory cap on the level of damages under s18 of the Landlord and Tenant Act 1927) that the parties' minds would start to concentrate on the actual amounts that could be recovered in court and sensible 


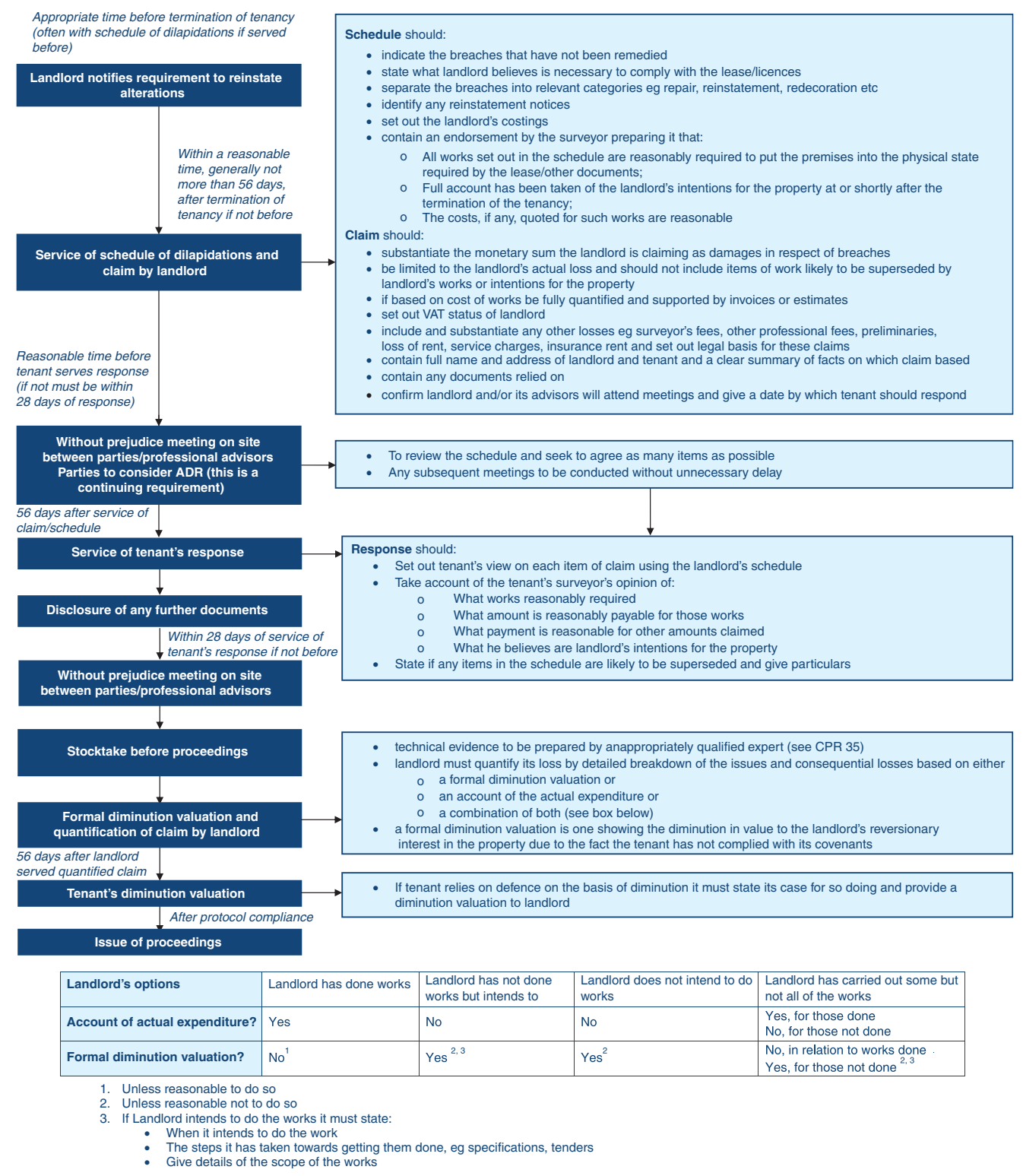

Figure I: Guide to the Dilapidations Protocol

discussions would commence. By then, however, substantial costs, both surveying and legal, would have been incurred.

\section{PHYSICAL STATE OF PREMISES}

The Protocol deals with all claims relating to the physical state of premises at the termination of a tenancy. This includes breaches of covenant by the tenant relating to repairs, reinstatement and redecoration.

\section{THE SCHEDULE}

A schedule of dilapidations should be served within a reasonable time after the termination of the tenancy (generally 56 days) in the form attached to the Protocol. The 
landlord may serve a schedule earlier but, if so, should confirm at the end of the tenancy that the situation is the same as in the earlier schedule or serve a further one.

The schedule should state the tenant's outstanding breaches, state what works the landlord considers necessary and set out the landlord's costings. The breaches should be listed by category, for example repair, reinstatement, rather than by room and the schedule should identify any relevant notices that have been served.

\section{THE ENDORSEMENT}

The schedule should contain an endorsement by the surveyor preparing it that in his opinion: (i) all the works set out in the schedule are reasonably required by the terms of the lease in order to put the premises into the physical state required by the terms of the lease (and any licences or other relevant documents); (ii) that full account has been taken of the landlord's intentions for the property at or shortly after the termination of the tenancy; and (iii) that the costs, if any, quoted for such works are reasonable. In giving this endorsement, the surveyor should have regard to the principles laid down by the RICS Guidance Note on Dilapidations.

\section{THE CLAIM}

The claim, which should be served within the same timetable for serving the schedule, sets out and should substantiate the monetary sum the landlord is claiming as damages in respect of the breaches. If the claim is based on costs of the works, it should be supported by invoices or a detailed estimate. The claim should also set out the landlord's VAT status and quantify any additional claims, for example loss of rent, professional fees, preliminaries, explaining on what basis these are claimed, that is, as part of the damages claim or under an express provision in the lease.

The claim should confirm that the landlord and/or its advisers will attend a without prejudice meeting and set out the date by which the tenant should respond (56 days being reasonable).

\section{LANDLORD'S LOSS}

The claim should be restricted to the landlord's loss that is not necessarily the same as the cost of the works to remedy the breaches. It should not include any items of work that are not required, as they are likely to be superseded by works to be carried out by the landlord at or shortly after the termination of the tenancy or items likely to be superseded by the landlord's intentions for the property (ie 'supersession').

\section{TENANT'S RESPONSE}

The response, which should usually be served within 56 days of the claim, should set out the tenant's response to each part of the claim. It should take account of what works in the opinion of the tenant's surveyor are reasonably required for the tenant to comply with its covenants, what amount is reasonably payable for such works and the other sums claimed and should take account of what the tenant's surveyor believes are the landlord's intentions for the property.

If the tenant's surveyor considers there are 'supersession' issues, he should give particulars of this in the response and state to which items in the claim it is relevant. 


\section{DISCLOSURE/NEGOTIATIONS/ADR}

If further documents other than those disclosed with the claim and response are required, then the parties can agree to this or seek an order for pre-action disclosure under CPR part 31.

The parties are encouraged to meet on site, to have without prejudice discussions, before the tenant serves his response, but in any event within 28 days of service of that response in the hope of narrowing issues and reaching a settlement.

The Protocol encourage the parties to use alternative dispute resolution procedures and reminds them that they may be required by the court to provide evidence that alternative means of resolving the dispute were considered.

\section{FORMAL DIMINUTION VALUATION}

The landlord can substantiate its loss by an account of actual expenditure or a combination of this and a formal diminution valuation. If the works have been done, the claim can be based upon the actual expenditure and a formal valuation will not normally be needed. If the landlord intends to do the works, it must state when it intends to do so and steps taken in this regard, for example preparing specifications or inviting tenders, and identifying the scope of the works. It should provide a diminution valuation unless in all the circumstances it would be reasonable not to. If the landlord does not intend to do the works, it should generally provide a formal valuation.

If the tenant is to rely on a defence on the basis of diminution valuation, it must also provide a formal valuation at this stage, usually not more than 56 days after the landlord has served its claim.

If a formal diminution valuation is produced, it should be prepared by a valuer. Only one valuation is required, which takes account of both s18(1) in relation to covenants to repair and common law principles of loss for other covenants.

\section{THE FUTURE}

The full text of the Protocol can be found at www.pla.org.uk. The PLA are consulting with Her Majesty's Court Service regarding the formal adoption of the Protocol under the Civil Procedure Rules. In the meantime, its latest edition has again been formally endorsed by the RICS in their new Guidance Note on Dilapidations. 